\title{
A Pectic Polysaccharide from Sijunzi Decoction Promotes the Antioxidant Defenses of SW480 Cells
}

\author{
Chao Huang ${ }^{1,3,+}$, Zhongkai Zhu ${ }^{2,+}$, Xiyue Cao ${ }^{1,3}$, Xingfu Chen ${ }^{5}$, Yuping Fu ${ }^{2,3}$, \\ Zhengli Chen ${ }^{1,3}$, Lixia Li ${ }^{2,3}$, Xu Song ${ }^{2,3}$, Renyong Jia ${ }^{3}$, Zhongqiong Yin ${ }^{2,3}$, Gang Ye ${ }^{2}$, \\ Bin Feng ${ }^{4}$ (D) and Yuanfeng Zou $2,3, *$ (1)
}

1 Laboratory of Experimental Animal Disease Model, College of Veterinary Medicine, Sichuan Agricultural University, Chengdu 611130, China; huangchao@sicau.edu.cn (C.H.); caoxys@hotmail.com (X.C.); chzhli75@163.com (Z.C.)

2 Natural Medicine Research Center, College of Veterinary Medicine, Sichuan Agricultural University, Chengdu 611130, China; zhongkaizhu6@163.com (Z.Z.); yupingfu424@163.com (Y.F.); lilixia905@163.com (L.L.); songx@sicau.edu.cn (X.S.); yinzhongq@163.com (Z.Y.); gangyee206@163.com (G.Y.) Key Laboratory of Animal Disease and Human Health of Sichuan Province, College of Veterinary Medicine, Sichuan Agricultural University, Chengdu 611130, China; jiary@sicau.edu.cn

4 Animal Nutrition Institute, Sichuan Agricultural University, Chengdu 611130, China; fengbin@sicau.edu.cn

5 Key Laboratory of Crop Ecophysiology and Farming System in Southwest China, Ministry of Agriculture, College of Agronomy, Sichuan Agricultural University, Chengdu 611130, China; chenxf64@sohu.com

* Correspondence: yuanfengzou@sicau.edu.cn; Tel.: +86-028-86291348

+ These authors contributed equally to this work.

Received: 28 July 2017; Accepted: 11 August 2017; Published: 12 August 2017

\begin{abstract}
Sijunzi Decoction (SJZD) is a formula used for the treatment of spleen deficiency and gastrointestinal diseases in Traditional Chinese Medicine. Polysaccharides are reported to be the main components of SJZD responsible for its bio-functions. However, highly purified and clearly characterized polysaccharides from SJZD are not well described. Here we obtained a purified polysaccharide (SJZDP-II-I) from SJZD using ion exchange chromatography and gel filtration. Structure analysis by FT-IR and NMR identified SJZDP-II-I as a typical pectic polysaccharide with homogalacturonan and rhamnogalacturonan type I regions and arabinogalactan type I and II as side chains. In vitro studies indicated that SJZDP-II-I treatment could significantly enhance the total antioxidant capacity of SW480 cells, resulting from the promoted expressions of antioxidant enzymes and their master regulator PGC- $1 \alpha$, which would be valuable for further research and applications.
\end{abstract}

Keywords: Sijunzi Decoction; SJZD; pectic polysaccharide; oxidative stress; antioxidant defense

\section{Introduction}

As a conventional Traditional Chinese Medicine Formula (TCMF), Sijunzi Decoction (SJZD), consisting of four crude herbs (Panax ginseng, Atractylodes macrocephala, Poria cocos and Glycyrrhiza uralensis) in the ratio of 3:3:3:2, has been widely applied for over one thousand years in the treatment of gastrointestinal diseases, such as stomach aches, rugitus, nausea, vomiting and diarrhea $[1,2]$. Modern pharmacological studies have further revealed its potential effects on the immune system activation and cancer treatment [1,3,4]. Due to the expensive price of Panax ginseng, Codonopsis pilosula, with similar biological activities, has been used as a substitute for more than hundreds of years in SJZD [5,6]. Flavonoids, coumarins, triterpenoid and polysaccharides were reported to be the main components of SJZD [7], and polysaccharides were considered as the most abundant and effective component [4].

The functions of polysaccharides from each herb of SJZD were widely reported. C. pilosula polysaccharides showed several bioactivities, such as enhancement of lymphocyte proliferation [8], 
improvement of the compensatory hematopoiesis of spleen [9], antitumor activity [10], and immunomodulating activity [11]. Additionally, polysaccharides from A. macrocephala were reported to regulate the gut microbes and were widely used in the treatment of chronic intestinal diseases [12]. P. cocos and G. uralensis polysaccharides showed antioxidant and anti-infectious capacity, respectively $[13,14]$. However, highly purified polysaccharides from SJZD with clearly characterized structures are not well described. Han et al. have found that the total polysaccharides from SJZD could enhance the proliferation of intestinal epithelial cells [15]. Liu et al. have also reported that the total SJZD polysaccharides could improve intestinal restitution and protect against indomethacin-induced damage of intestinal epithelial cells [16]. Three major SJZD polysaccharide fractions were isolated by Wang et al., the monosaccharide components of which were characterized, but further structural information remains unclear [17]. Therefore, it is of interest and necessity to deepen the study of the structural properties of polysaccharides from SJZD.

Reactive oxygen species (ROS), widely generated during life processes, are involved in gene transcription signal transduction, and regulation of the soluble guanylate cyclase activity of cells [18]. The concentration of ROS is precisely controlled by antioxidants, both enzymatic and non-enzymatic. When the balance between ROS production and antioxidant defenses is broken, excessive ROS accumulation may result in progressive oxidative damage to lipids, proteins and DNA, which is collectively referred to as 'oxidative stress' [19]. The intestine is vulnerable to oxidative stress, due to its constant exposure to diet-derived oxidants, mutagens, and iron salts as well as endogenously generated ROS [20]. Therefore, antioxidant defenses are critical for intestinal functions, impairment of which is widely involved in intestinal disorders, such as inflammatory bowel diseases and intestinal absorption dysfunctions [21,22], making the identification of molecules that can promote the antioxidant capability in intestine very important.

In this work, ion exchange chromatography and gel filtration were used to purify polysaccharides from SJZD, and three fractions-SJZDP-I-I, SJZDP-I-II, SJZDP-II-I-were obtained. Characterization was performed based on bioassay guidance, from which SJZDP-II-I was selected. Structural analysis by FT-IR and NMR identified SJZDP-II-I as a typical pectic polysaccharide with HG regions, RG-I regions and AG-I/AG-II as side chains. Further, we have found that the treatment with SJZDP-II-I could promote the expressions of antioxidant enzymes and their master regulator PGC-1 $\alpha$, resulting in significant enhancement of the total antioxidant capacity of SW480 cells. These findings reveal a new perspective on the role of the pectic polysaccharides from SJZD in the oxidative defenses, which should elicit interest for further applications.

\section{Results and Discussion}

\subsection{Fractionation of Pectic Polysaccharides from SJZDP}

The crude water extracted SJZDP (200 mg) was subjected to anion exchange chromatography, whereby two acidic fractions, SJZDP-I (25 mg) and SJZDP-II (54 mg), were obtained. These two acidic fractions were further fractionated using gel filtration. After separation on a gel filtration column, SJZDP-I-I (8 mg) and SJZDP-I-II (13 mg) were obtained from SJZDP-I, and one fraction (SJZDP-II-I, $41 \mathrm{mg}$ ) was purified from SJZDP-II (Figure 1). SJZDP-II-I was chosen for structure elucidation as the other two fractions showed no activity in promoting the antioxidant defenses of SW480 cells (data not shown).

\subsection{Chemical Composition of Polysaccharide}

The monosaccharide composition of the isolated polysaccharide fractions was determined by GC analysis after methanolysis and TMS-derivatization. As shown in Table 1, the monosaccharide compositions of the three isolated fractions were quite different. 

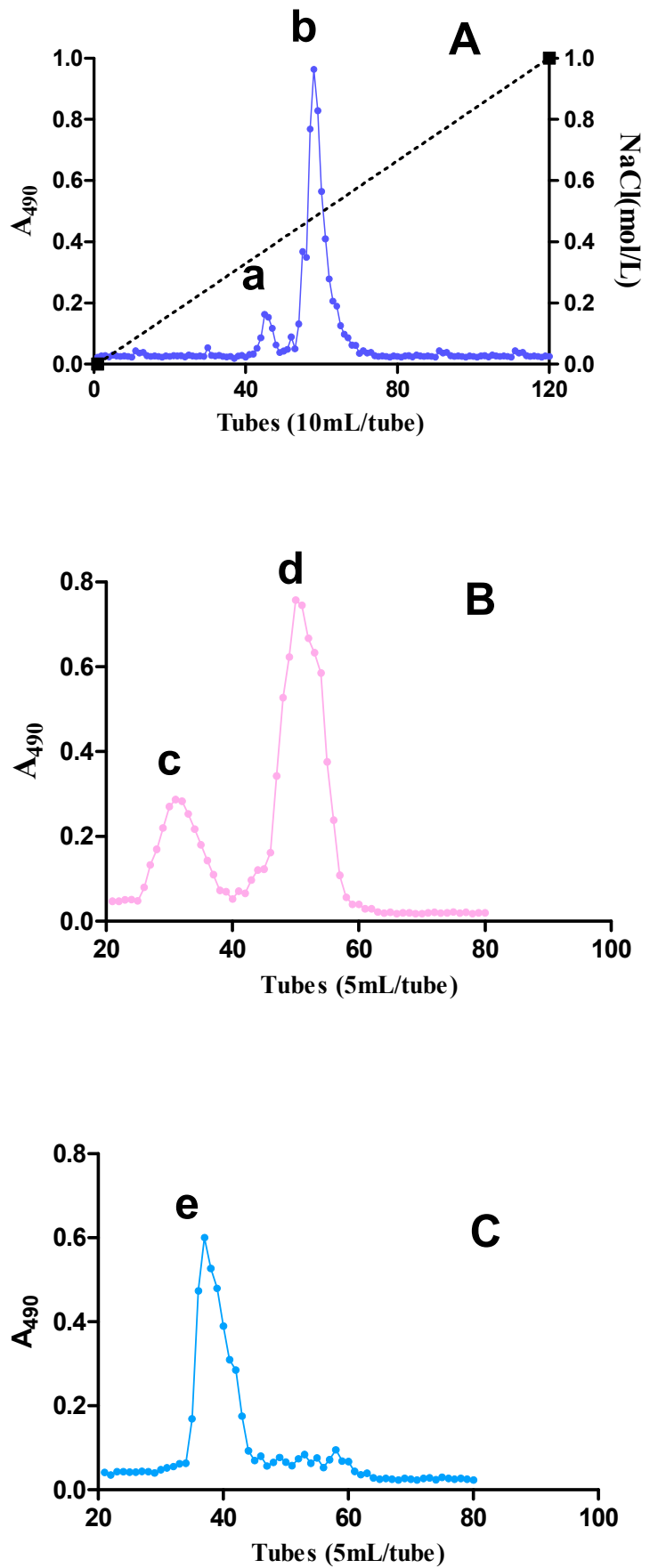

Figure 1. The carbohydrate elution profiles were monitored using the phenol-sulfuric acid assay (A490 is the absorbance at $490 \mathrm{~nm}$ ). (A) Ion exchange chromatography elution profile of SJZDP: (a) SJZDP-I and (b) SJZDP-II; (B) Gel filtration elution profile of SJZDP-I: (c) SJZDP-I-I and (d) SJZDP-I-II; (C) Gel filtration elution profile of SJZDP-II: (e) SJZDP-II-I.

Fraction SJZDP-I-I was mainly composed of arabinose (Ara), galactose (Gal) and glucose (Glc), accounting for $86.0 \mathrm{~mol} \%$ of the total carbohydrates, while the fraction SJZDP-I-II mainly consisted of Ara (18.9 mol \%) and Glc (66.9 mol \%). Compared to fraction SJZDP-I-I and SJZDP-I-II, the fraction SJZDP-II-I contained a higher amount of uronic acids. The fraction SJZDP-II-I was mainly composed of Ara, Gal and GalA, which accounted for $90.7 \mathrm{~mol} \%$ of the total carbohydrates. The differences in monosaccharide composition between fractions SJZDP-I-I, SJZDP-I-II and SJZDP-II-I may explain the 
different activities in promoting the antioxidant defenses of SW480 cells. The obtained monosaccharide compositions of the polysaccharide fractions are different from those of previous reports, as SJZPS-Vb-1 and SJZPS-Vb-2 were mainly composed of Glc, Gal and mannose (Man) [23], and such differences may result from the different methods of extraction and purification. As SJZDP is a mixture of four herbs, the obtained monosaccharide compositions of polysaccharides may derive from different herbs. The monosaccharide Ara, Gal, Rha, Man and xylose (Xyl), may come from any of the four herbs, since the polysaccharides from all four of these herbs contained these monosaccharides [11,24-26]. Additionally, a previous report on polysaccharides from P. cocos indicated that the Glc present in SJZDP came mainly from P. cocos [27].

Size exclusion chromatography using dextran standards was applied to determine the average molecular weight of the polysaccharide fractions obtained. The results indicated that the fraction SJZDP-I-I (351.0 kDa) has the highest Mw, followed by SJZDP-II-I (171.9 kDa) and SJZDP-I-II (16.9 kDa). The Mw of these three fractions were different from those of polysaccharides SJZPS-Vb-1 (38.3 kDa) and SJZPS-Vb-2 (28.0 kDa) as previously reported [23].

Table 1. Monosaccharide compositions (mol \%) and $\mathrm{Mw}$ of polysaccharide fractions SJZDP-I-I, SJZDP-I-II and SJZDP-II-I, isolated from SJZDP.

\begin{tabular}{cccc}
\hline & SJZDP-I-I & SJZDP-I-II & SJZDP-II-I \\
\hline Ara $^{\mathrm{a}}$ & 51.2 & 18.9 & 32.8 \\
Rha $^{\mathrm{a}}$ & 2.3 & 1.7 & 5.0 \\
Fuc $^{\mathrm{a}}$ & 2.1 & n.d. & 0.4 \\
Xyl $^{\mathrm{a}}$ & n.d. & 2.4 & 0.4 \\
$\mathrm{Man}^{\mathrm{a}}$ & 3.7 & 1.4 & 0.4 \\
$\mathrm{Gal}^{\mathrm{a}}$ & 23.6 & 4.7 & 40.5 \\
Glc $^{\mathrm{a}}$ & 11.2 & 66.9 & 1.5 \\
$\mathrm{GlcA}^{\mathrm{a}}$ & 0.8 & n.d. & 1.5 \\
$\mathrm{GalA}^{\mathrm{a}}$ & 5.2 & 4.0 & 17.4 \\
$\mathrm{Mw}(\mathrm{kDa})$ & 351.0 & 16.9 & 171.9 \\
\hline
\end{tabular}

n.d. not detected. ${ }^{a}$ mol \% related to total content of the monosaccharides arabinose (Ara), rhamnose (Rha), fucose (Fuc), mannose (Man), galactose (Gal), glucose (Glc), Glucuronic acid (GlcA) and Galacturonic acid (GalA).

\subsection{Determination of the Glycosidic Linkages}

The purified fraction SJZDP-II-I was analyzed for the types of glycosidic linkages using GC-MS after conversion to partially methylated alditol acetates (Table 2).

Table 2. The glycosidic linkage (mol \%) present in the fraction SJZDP-II-I isolated from SJZDP.

\begin{tabular}{ccc}
\hline & Linkage Type & mol \% \\
\hline Ara & $\mathrm{T} f$ & 22.7 \\
& $1 \rightarrow 5 f$ & 3.7 \\
& $1 \rightarrow 3,5 f$ & 6.4 \\
Rha & $\mathrm{T} p$ & 0.4 \\
& $1 \rightarrow 2 p$ & 1.8 \\
& $1 \rightarrow 2,4 p$ & 2.8 \\
Gal & $\mathrm{T} p$ & 2.4 \\
& $1 \rightarrow 4 p$ & 10.7 \\
& $1 \rightarrow 3 p$ & 2.2 \\
& $1 \rightarrow 6 p$ & 5.1 \\
& $1 \rightarrow 3,6 p$ & 20.1 \\
Glc & $\mathrm{T} p$ & 1.5 \\
GlcA & $\mathrm{T} p$ & 1.5 \\
GalA & $\mathrm{T} p$ & 0.9 \\
& $1 \rightarrow 4 p$ & 16.5 \\
\hline
\end{tabular}


As shown in the table, fraction SJZDP-II-I contained linkage units typical of pectic polysaccharides. The presence of 1,4- linked GalA indicates the presence of a homogalacturonan (HG) backbone, while 1,4-linked GalA with 1,2 and 1,2,4-linked Rha indicates a rhamnogalacturonan I region (RG-I) in the polymers [28]. The highly branched RG-I is known as the "hairy region" of the pectin, which normally consists of branching chains, such as arabinans, galactans and/or arabinogalactans (AG) [29]. Fraction SJZDP-II-I contained a high amount of 1,4-linked Gal units, suggesting that the polymers are rich in arabinogalactan type I (AG-I) structures, and the presence of 1,3-; 1,6-; and 1,3,6-linked Gal indicates the presence of arabinogalactan type II (AG-II) structures. The linkage units of fraction SJZDP-II-I were different from those of fractions SJZPS-Vb-1 and SJZPS-Vb-2 from SJZD, as they contain different monosaccharide compositions [23]. However, for the linkage types of Gal, fraction SJZDP-II-I contained similar linkage types with fractions SJZPS-Vb-1 and SJZPS-Vb-2, such as terminal linked, 1,6-linked and 1,3,6-linked Gal. The linkage type of fraction SJZDP-II-I was similar to those of polysaccharides from $C$. pilosula, but with a different ratio [11].

\subsection{Structural Features}

As shown in Figure 2, the FT-IR chromatogram of fraction SJZDP-II-I showed characteristic absorptions of polysaccharides [30]. The absence of absorption bands at $1735 \mathrm{~cm}^{-1}$ and $1250 \mathrm{~cm}^{-1}$ indicated that the GalA units of fraction SJZDP-II-I were not esterified [31,32]. These were different from the polysaccharides isolated from C. pilosula [11] and G. uralensis [26], while polysaccharides from C. pilosula contain bands at $1735 \mathrm{~cm}^{-1}$ and $1250 \mathrm{~cm}^{-1}$, and polysaccharides from G. uralensis only contain a $1735 \mathrm{~cm}^{-1}$ band.

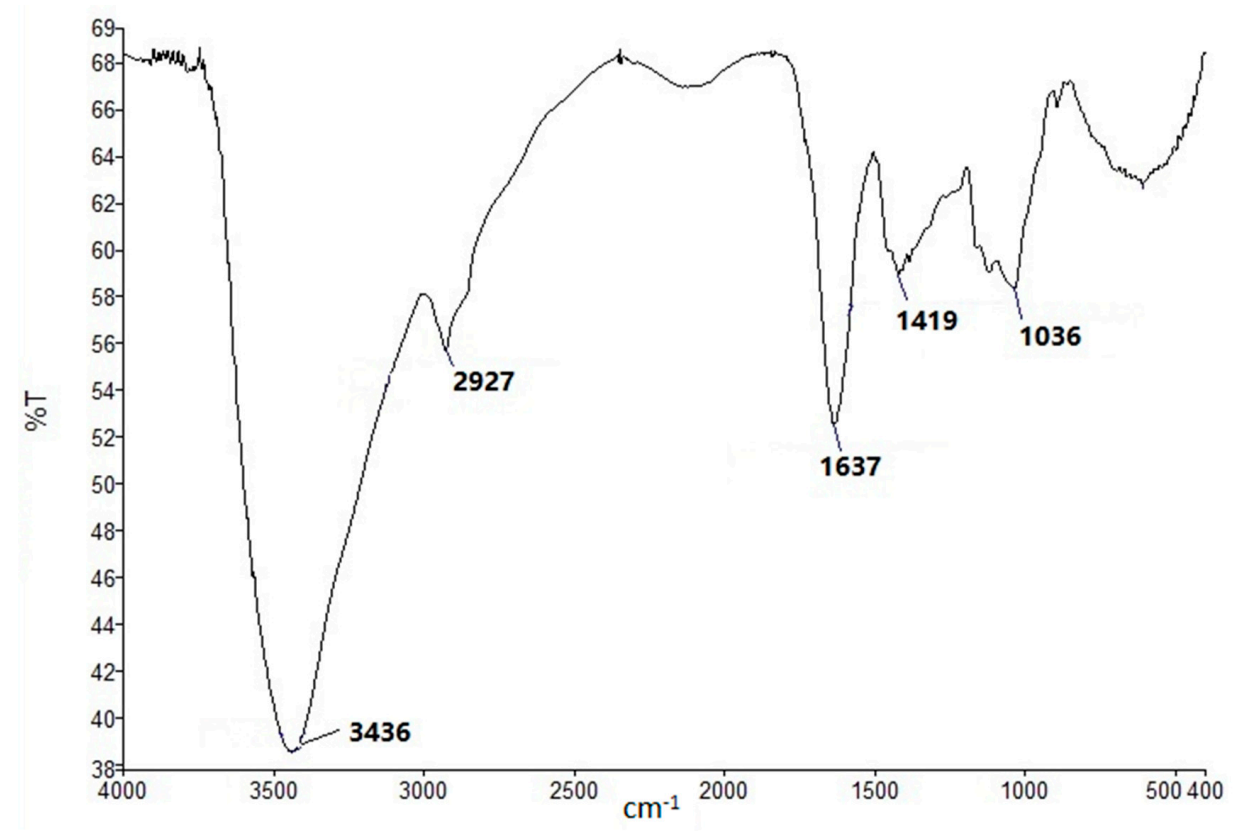

Figure 2. FT-IR spectra of fraction SJZDP-II-I.

The polysaccharide fraction SJZDP-II-I was also characterized by 1D NMR spectroscopy and the chemical shift values compared with data from the literature [11,33-36]. Typically, the anomeric ${ }^{1} \mathrm{H}$ signals of $\alpha$-pyranoside are found over $5 \mathrm{ppm}$ while those of $\beta$-pyranoside are at less than $5 \mathrm{ppm}$ [37]. As shown in Figure 3, the ${ }^{1} \mathrm{H}-\mathrm{NMR}$ spectrum of polysaccharide fraction SJZDP-II-I contained five main anomeric protons at 5.11, 5.04,5.02, 4.95 and $4.51 \mathrm{ppm}$, indicating the existence of both $\alpha$ and $\beta$-configurations in the polysaccharide fraction SJZDP-II-I. The weak proton signal at 1.18 and $1.26 \mathrm{ppm}$ indicated the presence of a methyl group of Rha in the fraction [35]. The ${ }^{13} \mathrm{C}$ signals at $175.74 \mathrm{ppm}$ corresponded to carbonyl carbon of unesterified $\alpha-1,4-\mathrm{Gal} p \mathrm{~A}$, and the $103.14 \mathrm{ppm}$ 
corresponded to C- 1 of $\alpha-1,4$-GalpA. Other signals such as 107.29 ppm corresponded to $\alpha$ - L-Araf, while $106.80 \mathrm{ppm}, 106.33 \mathrm{ppm}$ and $104.29 \mathrm{ppm}$ were corresponded to $\beta$-D-Galp [33]. The signals at $16.75 \mathrm{ppm}$ represented the C-6 of $\alpha$-L-Rha [36]. These results suggested that fraction SJZDP-II-I was a typical pectic polysaccharide, with HG regions, RG-I regions and AG-I/AG-II side chains, which was consistent with the monosaccharide composition results.

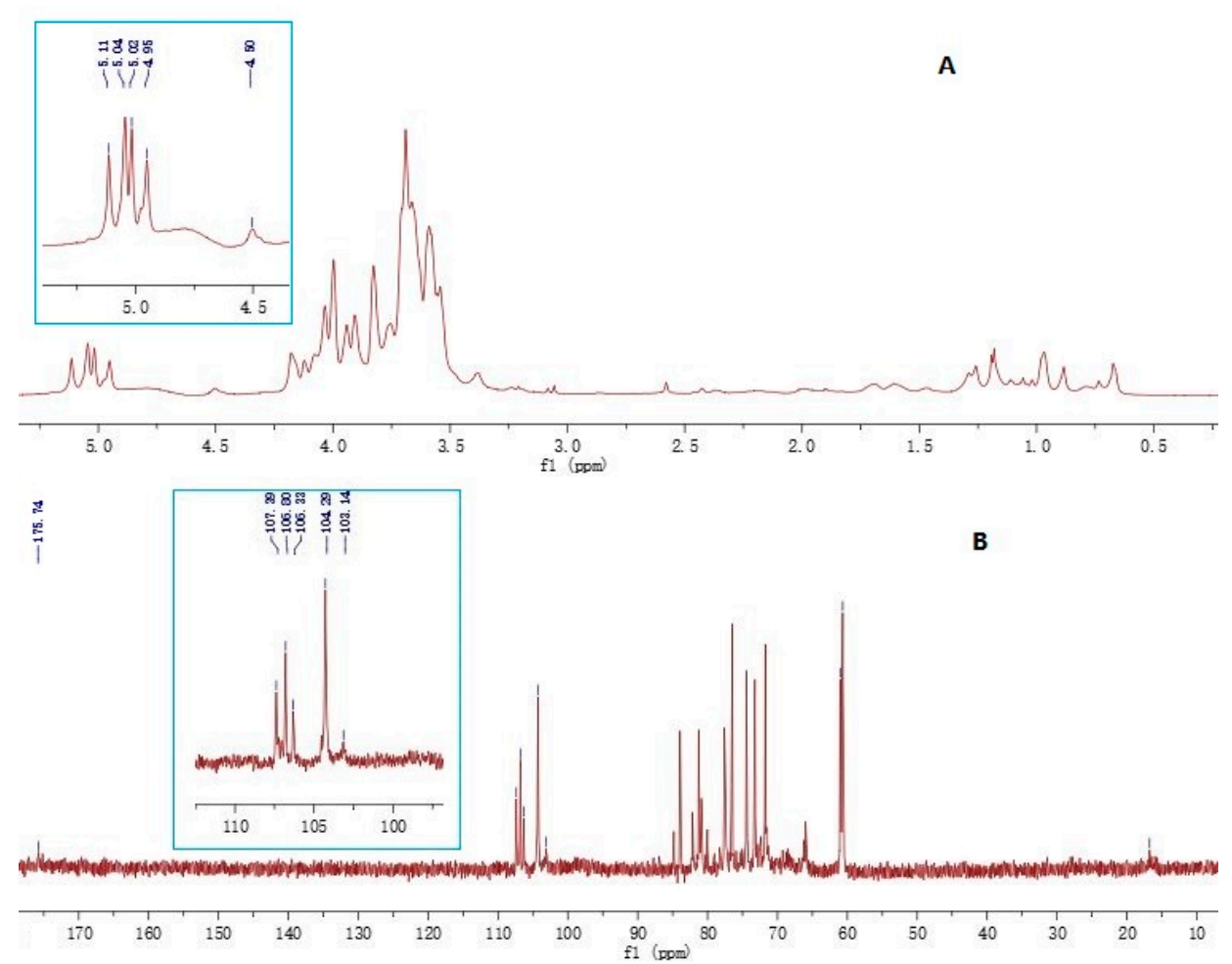

Figure 3. The ${ }^{1} \mathrm{H}$ - and ${ }^{13} \mathrm{C}-\mathrm{NMR}$ spectra of polysaccharide fraction SJZDP-II-I. (A) ${ }^{1} \mathrm{H}-\mathrm{NMR}$ spectra of SJZDP-II-I; $(\mathbf{B}){ }^{13}$ C-NMR spectra of SJZDP-II-I.

\subsection{SJZDP-II-I Treatment Didn't Affect the Proliferation of SW480 Cells}

Total SJZDP was reported to enhance cell proliferation [15], but no such activity of was found in the fraction SJZDP-II-I of this study. SW480 cells, derived from colon adenocarcinoma, exhibited similar proliferation rates after SJZDP-II-I treatment under different doses. Additionally, SJZDP-II-I exhibited no cellular toxicity at the concentration up to $40 \mu \mathrm{g} / \mathrm{mL}$ (Figure 4).

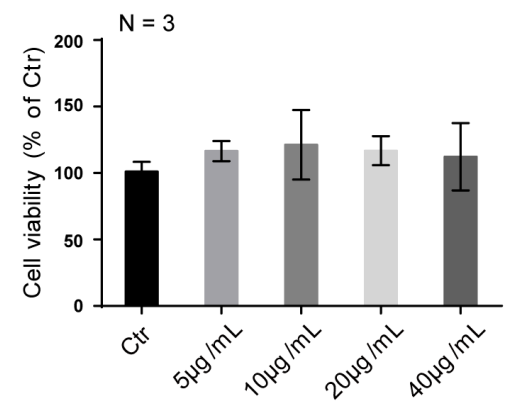

Figure 4. SJZDP-II-I treatment didn't affect the proliferation of SW480 cells. Quantification shows no enhancement of cell proliferation and cytotoxicity of SJZDP-II-I in SW480 cells, with a concentration up to $40 \mu \mathrm{g} / \mathrm{mL}$. Error bars indicate SD. Data are shown as mean $\pm \mathrm{SD}$ of triplicates of one experiment, and the experiment was repeated 3 times. 


\subsection{SJZDP-II-I Promoted the Antioxidant Defense of SW480 Cells}

SAs SJZD is widely used in gastrointestinal disorders, so it was reasonable to expect that SJZDP-II-I would affect the functions of these organs [1,2]. Total SJZD polysaccharides have been reported to promote the restoration of intestinal function by regulating intestinal homeostasis [2]. A growing body of evidence indicates that cellular oxidative stress and redox status are widely implicated in intestinal homeostasis, affecting cellular proliferation, apoptosis, metabolic processes, as well as the balance of intestinal microecology $[21,38,39]$. In this study, we found that SJZDP-II-I treatment could remarkably increase the total antioxidant capacity (TAC) of SW480 cells, but little antioxidant capacity of SJZDP-II-I itself was detected according to an in vitro assay (Figure 5). Thus, the enhanced TAC may result from the increased levels of antioxidants induced by the enhancement of gene expression in SW480 cells themselves, but not SJZDP-II-I. In order to clarify this, the expressions of representative antioxidant enzymes were evaluated, showing a robust increase of these enzymes after SJZDP-II-I treatment, as well as the master regulator of antioxidant defense-PGC- $1 \alpha$ (Figure 5). These results indicated that SJZDP-II-I could protect SW480 cells from oxidative stress through the promotion of antioxidant enzymes' expression, and suggested that SJZDP-II-I may participate in the regulation of intestinal homeostasis through the redox status control of the intestine.
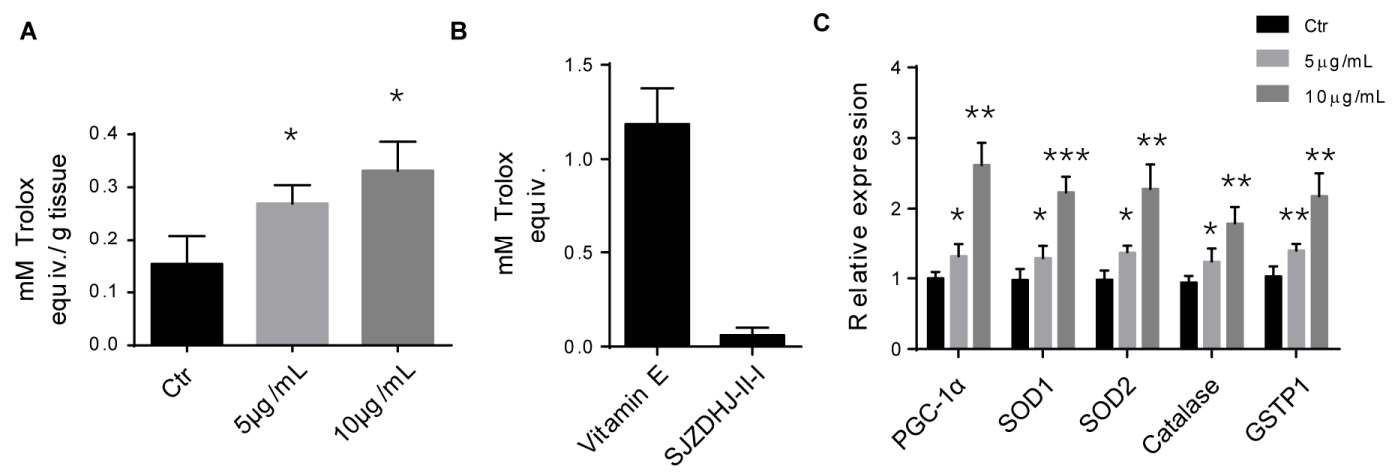

Figure 5. SJZDP-II-I treatment promoted the expression of antioxidant defense genes. (A) Quantification showed an increase of total antioxidant capability in SW480 cells after SJZDP-II-I treatment. Error bars indicated SD. ${ }^{*} p<0.05 . N=3$; (B) In vitro assay displayed little antioxidant capacity of SJZDP-II-I when it was compared with Vitamin E. $N=3$; (C) qRT-PCR showed robust increased mRNA levels of PGC-1 $\alpha$ and antioxidant enzymes after SJZDP-II-I treatment in SW480 cells. Error bars indicated SD. ${ }^{*} p<0.05,{ }^{* *} p<0.01,{ }^{* * *} p<0.001 . N=3$.

\section{Materials and Methods}

\subsection{Preparation of Polysaccharides}

Sijunzi Decoction (SJZD) was derived from four herbs, C. pilosula, G. uralensis, P. cocos and A. macrocephala, in a ratio of 3:3:3:2 by weight. All prepared slices of these four herbs were purchased from Fushoutang Pharmacy (Chengdu, China). SJZD was used for the preparation of polysaccharides (SJZDP) as described previously [16]. Dried herbs (55 g) were soaked in distilled water $(440 \mathrm{~mL})$ for $30 \mathrm{~min}$ at room temperature and then extracted twice at $100{ }^{\circ} \mathrm{C}$ for $4 \mathrm{~h}$. The extract fractions were combined and concentrated by rotary evaporation. The concentrated extracts were subjected for dialysis (3500 Da cut-off, Beijing Rui Da Heng Hui Science Technology Development Co. Ltd., Beijing, China) in running water for 2 days. After dialysis, the extracts were lyophilized, and named SJZDP.

The SJZDP was purified by anion exchange chromatography and gel filtration. First, the SJZDP (200 $\mathrm{mg}$ ) was dissolved in distilled water $(10 \mathrm{~mL})$, filtered through a $0.45 \mu \mathrm{m}$ filter and applied to a DEAE Sepharose (Fast Flow, FF) column $(5 \mathrm{~cm} \times 40 \mathrm{~cm}$, Beijing Rui Da Heng Hui Science Technology Development Co. Ltd.). The neutral fraction was eluted with distilled water at $2 \mathrm{~mL} / \mathrm{min}$, while the acidic fractions were eluted with a linear $\mathrm{NaCl}$ gradient in water $(0-1.5 \mathrm{M})$ at $2 \mathrm{~mL} / \mathrm{min}$. 
The elution profiles were monitored using the phenol-sulfuric acid assay [40]. The related fractions were pooled, dialyzed at cut-off $3500 \mathrm{Da}$ against distilled water to remove of $\mathrm{NaCl}$, and lyophilized. Second, the acidic fractions ( $50 \mathrm{mg}$ ) were dissolved in elution buffer $(10 \mathrm{mM} \mathrm{NaCl})$, filtered through a Millipore filter $(0.45 \mu \mathrm{m})$, and subjected to gel filtration after application on a Sepharose 6FF column $(2.5 \mathrm{~cm} \times 100 \mathrm{~cm}$, Beijing Rui Da Heng Hui Science Technology Development Co. Ltd., Beijing, China, and eluted with $10 \mathrm{mM} \mathrm{NaCl}$ at $1.0 \mathrm{~mL} / \mathrm{min}$. Fractions were pooled based on the elution profile, as determined by the phenol-sulfuric acid assay, dialyzed and lyophilized.

\subsection{Chemical Compositions and Linkage Determination}

The monosaccharide compositions of the fractions was determined by gas chromatography of the trimethylsilylated (TMS) derivatives of the methyl glycosides obtained after methanolysis with $3 \mathrm{M}$ hydrochloric acid in anhydrous methanol for $24 \mathrm{~h}$ at $80{ }^{\circ} \mathrm{C}$ [41]. Mannitol was used as an internal standard. The TMS derivatives were analyzed by capillary gas chromatography on a Focus GC (Thermo Scientific, Milan, Italy). Glycosidic linkage elucidation was performed by methylation studies. Prior to methylation, the uronic acids at polymeric level were reduced with $\mathrm{NaBD}_{4}$ to their corresponding neutral sugars [42]. After reduction of the polymers, methylation, hydrolysis, reduction and acetylation were carried out [43]. The derivatives were analyzed by GC-MS using a GCMS-QP2010 (Shimadzu, Kyoto, Japan) attached to a Restek Rxi-5MS column ( $30 \mathrm{~m} ; 0.25 \mathrm{~mm}$ i.d.; $0.25 \mu \mathrm{m}$ film). The injector temperature was $280^{\circ} \mathrm{C}$, the ion source temperature $200^{\circ} \mathrm{C}$ and the interface temperature $300{ }^{\circ} \mathrm{C}$. The column temperature was $80^{\circ} \mathrm{C}$ when sample was injected, then increased $10^{\circ} \mathrm{C} / \mathrm{min}$ to $140{ }^{\circ} \mathrm{C}$, followed by $4{ }^{\circ} \mathrm{C} / \mathrm{min}$ to $210^{\circ} \mathrm{C}$ and then $20^{\circ} \mathrm{C} / \mathrm{min}$ to $300{ }^{\circ} \mathrm{C}$. Helium was the carrier gas (pressure control: $80 \mathrm{kPa}$ ). The compound corresponding to each peak was characterized by the interpretation of the retention times and the characteristic mass spectra. The estimation of the relative amounts of each linkage type was related to the total amount of each monosaccharide type as determined by methanolysis [44].

\subsection{Molecular Weight Determination}

The homogeneity and molecular weight of the native purified polysaccharide fractions were determined by size exclusion chromatography on a Hiload ${ }^{\mathrm{TM}} 16 / 60$ Superdex $^{\mathrm{TM}} 200$ prep grade column (GE Healthcare, Uppsala, Sweden) combined with the Äkta system (FPLC, Pharmacia Äkta, Amersham Pharmacia Biotech, Uppsala, Sweden). Dextran polymers (Pharmacia) of 10, 40, 70, 500 and $2000 \mathrm{kDa}$ were used as calibration standards [45].

\subsection{FT-IR and NMR Spectroscopy}

Approximately $1 \mathrm{mg}$ of polysaccharide sample was mixed with $150 \mathrm{mg}$ of dried $\mathrm{KBr}$ powder, and pressed into a $1 \mathrm{~mm}$ thick disk for the analysis using a PerkinElmer FT-IR spectrophotometer (PerkinElmer, Waltham, MA, USA). The IR spectra were recorded in the range of $4000-400 \mathrm{~cm}^{-1}$ [46]. ${ }^{1} \mathrm{H}-\mathrm{NMR}$ and ${ }^{13} \mathrm{C}-\mathrm{NMR}$ spectra of two main polysaccharides fractions were recorded in $\mathrm{D}_{2} \mathrm{O}$ solution at $25^{\circ} \mathrm{C}$ on an AV600 spectrometer (600 MHz, Bruker, Rheinstetten, Germany) after deuterium exchange three times by freeze-drying in $\mathrm{D}_{2} \mathrm{O}$.

\subsection{Cell Culture}

SW480 cells were routinely cultured in DMEM (Gibco, Waltham, MA, USA), supplemented with $10 \%$ FBS in an incubator under an atmosphere of $5 \% \mathrm{CO}_{2}$ at $37^{\circ} \mathrm{C}$. Cells were plated in 6-well cell plates $\left(1 \times 10^{6}\right.$ cells per well); $12 \mathrm{~h}$ after the polysaccharide supplement, cells were collected for gene expression detection and ABTS Radical Scavenging Activity Assay. Meanwhile, cell viability was assayed $12 \mathrm{~h}$ after the polysaccharide treatment in 96-well cell plate $\left(5 \times 10^{4}\right.$ cells per well), using CCK-8 kit. 


\subsection{Cell Viability Assay}

Cell viability was measured by Cell Counting Kit-8 (CCK-8) system (Dojindo, CK04-11, Minato-ku, Tokyo, Japan) according to the manufacturer's instructions. Briefly, CCK-8 solution $(10 \mu \mathrm{L}$ per $100 \mu \mathrm{L}$ of medium in each well) was added, and the plates were then incubated at $37^{\circ} \mathrm{C}$ for $1 \mathrm{~h}$. The absorbance of each well was read at $450 \mathrm{~nm}$ using a microplate reader (Thermo, Waltham, MA, USA).

\subsection{Quantitative Realtime PCR}

RNA extraction from the intestine and real time PCR for antioxidant genes detection were performed as previously reported [47]. Briefly, SW480 cells were lysed with Trizol Regent (Invitrogen, Waltham, MA, USA), and the total RNA was extracted from the tissues according to the manufacturer's instructions. The quality of RNA was assessed by agarose gel and the concentration was measured with a spectrophotometer (NanoDrop 2000, Thermo Scientific, Shanghai, China). Total RNA was subjected to reverse transcription with a reverse transcriptase, according to the manufacturer's instructions (Fermentas, Waltham, MA, USA). Quantitative real-time PCR was performed using the Bio-Rad CFX96 system, and the relative gene expression was normalized to the internal control actin. Primer sequences for SYBR Green probes of the target genes are described in Table 3.

Table 3. qRT-PCR primers for antioxidant defense genes.

\begin{tabular}{|c|c|}
\hline \multirow{2}{*}{ SOD1 } & Fr 5'-CAAGCGGTGAACCAGTTGTG-3' \\
\hline & Rv 5'-TGAGGTCCTGCACTGGTAC-3' \\
\hline \multirow{2}{*}{ SOD2 } & Fr 5'-GCCTGCACTGAAGTTCAATG-3' \\
\hline & Rv 5'-ATCTGTAAGCGACCTTGCTC-3' \\
\hline \multirow{2}{*}{ Catalase } & Fr 5'-ACCCTCTTATACCAGTTGGC-3' \\
\hline & Rv 5'-GCATGCACATGGGGCCATCA-3' \\
\hline \multirow{2}{*}{ GSTP1 } & Fr 5'-ATGCCACCATACACCATTGTC-3' \\
\hline & Rv 5'-GGGAGCTGCCCATACAGAC-3' \\
\hline \multirow{2}{*}{ PGC- $1 \alpha$} & Fr 5'-CTCCCTGTGGATGAAGACGG-3' \\
\hline & Rv 5'-GCAAATCACAATCACAGGAT-3' \\
\hline
\end{tabular}

SOD, Superoxide dismutase; GSTP, Glutathione S-transferase Pi; PGC-1a, Peroxisome proliferator-activated receptor gamma coactivator 1-alpha.

\subsection{ABTS Radical Scavenging Activity Assay}

The total antioxidant capacity was evaluated using the ABTS method (Beyotime, Shanghai, China). ABTS radical cation $\left(\mathrm{ABTS}^{+}\right)$solution was produced by reacting ABTS stock solution with $2.45 \mathrm{mmol} / \mathrm{L}$ potassium persulfate in the dark at room temperature for 12-16 $\mathrm{h}$ before use, then it was diluted with $80 \%$ ethanol to adjust the absorbance to $0.70 \pm 0.05$ at $734 \mathrm{~nm}$. After that, $10 \mu \mathrm{L}$ of sample or Trolox standard was added into $200 \mu \mathrm{L}$ of diluted $\mathrm{ABTS}^{+}$solution. The absorbance at $734 \mathrm{~nm}$ was measured after 2-6 min in the dark at room temperature. Trolox, a water-soluble analogue of vitamin E, was used as the reference standard to prepare a calibration curve with a concentration range of $0.15-1.5 \mathrm{mM}$. Results were expressed as $\mathrm{mmol} / \mathrm{g}$ Trolox equivalent antioxidant capacity.

\subsection{Statistical Analysis}

Data represent the means and SD. One-way ANOVA and post hoc tests were performed for all statistical significance analysis using GraphPad Prism software (GraphPad Software, Inc., La Jolla, CA, USA). ${ }^{*} p<0.05,{ }^{* *} p<0.01,{ }^{* * *} p<0.001$. 


\section{Conclusions}

In summary, a purified polysaccharide from SJZD was obtained by using ion exchange chromatography and gel filtration. Structural analysis by FT-IR and NMR identified SJZDP-II-I as a typical pectic polysaccharide. Moreover, this SJZDP-II-I was shown to effectively promote the antioxidant defense capability in SW480 cells, which will be valuable for further research and applications.

Acknowledgments: This work was supported in part by the International Cooperation Projects of Science \& Technology Department of Sichuan Province (2017HH0093) and General Financial Grant from the China Postdoctoral Science Foundation (2016M602704), and the National Natural Science Foundation of China (31501200 to C.H). We are also grateful for valuable NMR discussions with Professor Berit Smestad Paulsen and Professor Frode Rise, University of Oslo, Norway.

Author Contributions: Yuanfeng Zou, Xingfu Chen and Zhongqiong Yin participated in designing the study and revised the manuscript. Yuping Fu, Lixia Li and Zhongkai Zhu prepared the extracts and purified all polysaccharide fractions. Xu Song and Yuanfeng Zou did the structural elucidation of polysaccharide obtained. Chao Huang, Gang Ye and Xiyue Cao performed the biological tests and analyzed the data. Zhengli Chen, Renyong Jia, Bin Feng and Chao Huang wrote the manuscript.

Conflicts of Interest: The authors declare no conflict of interest.

\section{References}

1. Liu, Y.; Yang, J.; Cai, Z. Chemical investigation on sijunzi decoction and its two major herbs Panax ginseng and Glycyrrhiza uralensis by LC/MS/MS. J. Pharm. Biomed. Anal. 2006, 41, 1642-1647. [CrossRef] [PubMed]

2. Yu, X.; Cui, Z.; Zhou, Z.; Shan, T.; Li, D.; Cui, N. Si-jun-zi decoction treatment promotes the restoration of intestinal function after obstruction by regulating intestinal homeostasis. Evid. Based Complement. Altern. Med. 2014, 2014, 928579. [CrossRef] [PubMed]

3. Wu, B.; Xuan, Z.-R. Progress in research on applying sijunzi decoction in treating digestive malignant tumor. Chin. J. Integr. Med. 2007, 13, 156-159. [CrossRef] [PubMed]

4. Liang, C.; Zhang, S.; Cai, Z. Effects of early intestinal application of sijunzi decoction on immune function in post-operational patients of gastrointestinal tumor. Chin. J. Integr. Tradit. West. Med. 2005, 25, 1070-1073.

5. Chinese Pharmacopoeia Commission. Pharmacopoeia of the People's Republic of China; China Medical Science Press: Beijing, China, 2015; Volume 1, pp. 392-393.

6. Wang, Y.-L.; Wang, X.-W.; Zeng, D.-M.; Liu, Y.-M. Microwave extraction and spectral analysis of the total polysaccharides in sijunzi decoction. Chin. J. Exp. Tradit. Med. Formulae 2012, 16, 025.

7. Wang, Y.; He, S.; Cheng, X.; Lu, Y.; Zou, Y.; Zhang, Q. UPLC-Q-TOF-MS/MS fingerprinting of traditional chinese formula SiJunZiTang. J. Pharm. Biomed. Anal. 2013, 80, 24-33. [CrossRef] [PubMed]

8. Sun, Y.; Liu, J. Structural characterization of a water-soluble polysaccharide from the roots of codonopsis pilosula and its immunity activity. Int. J. Biol. Macromol. 2008, 43, 279-282.

9. Zhang, X.; Zhu, C.; Li, H.; Lai, X.; Mo, J. Pharmacological action of polysaccharides from radix codonopsis on immune function and hematopoiesis in mice. Tradit. Chin. Drug Res. Clin. Pharmacol. 2003, 14, 174-176.

10. Xu, C.; Liu, Y.; Yuan, G.; Guan, M. The contribution of side chains to antitumor activity of a polysaccharide from codonopsis pilosula. Int. J. Biol. Macromol. 2012, 50, 891-894. [CrossRef] [PubMed]

11. Zou, Y.-F.; Chen, X.-F.; Malterud, K.E.; Rise, F.; Barsett, H.; Inngjerdingen, K.T.; Michaelsen, T.E.; Paulsen, B.S. Structural features and complement fixing activity of polysaccharides from Codonopsis pilosula Nannf. var. modesta L.T.Shen roots. Carbohydr. Polym. 2014, 113, 420-429. [CrossRef] [PubMed]

12. Wang, R.; Zhou, G.; Wang, M.; Peng, Y.; Li, X. The metabolism of polysaccharide from atractylodes macrocephala koidz and its effect on intestinal microflora. Evid. Based Complement. Altern. Med. 2014, 2014, 926381. [CrossRef] [PubMed]

13. Tang, J.; Nie, J.; Li, D.; Zhu, W.; Zhang, S.; Ma, F.; Sun, Q.; Song, J.; Zheng, Y.; Chen, P. Characterization and antioxidant activities of degraded polysaccharides from poria cocos sclerotium. Carbohydr. Polym. 2014, 105, 121-126. [CrossRef] [PubMed]

14. Wittschier, N.; Faller, G.; Hensel, A. Aqueous extracts and polysaccharides from liquorice roots (Glycyrrhiza glabra L.) inhibit adhesion of Helicobacter pylori to human gastric mucosa. J. Ethnopharmacol. 2009, 125, 218-223. [CrossRef] [PubMed] 
15. Han, L.; Wang, P.; Han, B. Total polysaccharide or four separate polysaccharides from sijunzi tang decoction to influence intestinal epithelial cell-6 proliferation in rat's intestinal epithelium. Chin. Rem. Clin. 2005, 5, 496-499.

16. Liu, L.; Han, L.; Wong, D.Y.; Yue, P.Y.; Ha, W.Y.; Hu, Y.H.; Wang, P.X.; Wong, R.N. Effects of Si-Jun-Zi decoction polysaccharides on cell migration and gene expression in wounded rat intestinal epithelial cells. Br. J. Nutr. 2005, 93, 21-29. [CrossRef] [PubMed]

17. Wang, R.; Peng, Y.; Meng, H.; Li, X. Protective effect of polysaccharides fractions from sijunzi decoction in reserpine-induced spleen deficiency rats. RSC Adv. 2016, 6, 60657-60665. [CrossRef]

18. McCord, J.M. The evolution of free radicals and oxidative stress. Am. J. Med. 2000, 108, 652-659. [CrossRef]

19. Finkel, T.; Holbrook, N.J. Oxidants, oxidative stress and the biology of ageing. Nature 2000, 408, $239-247$. [CrossRef] [PubMed]

20. Ames, B.N. Dietary carcinogens and anticarcinogens. Oxygen radicals and degenerative diseases. Science 1983, 221, 1256-1264. [CrossRef] [PubMed]

21. Circu, M.L.; Aw, T.Y. Intestinal redox biology and oxidative stress. Semin. Cell Dev. Biol. 2012, 23, $729-737$. [CrossRef] [PubMed]

22. Piechota-Polanczyk, A.; Fichna, J. The role of oxidative stress in pathogenesis and treatment of inflammatory bowel diseases. Naunyn Schmiedebergs Arch. Pharmacol. 2014, 387, 605-620. [CrossRef] [PubMed]

23. Zhu, C.; Gui, S.; Wang, P.; Chen, W. Purification and physi-chemical properties of polysaccharides sjzps-vb-1-2 from immunocompetence parts of sijunzi decoction. J. Chin. Med. Mater. 2003, 26, 751-753.

24. Cao, G.; Zhang, X.; Cong, X. The research progress of polysaccharides from atractylodes macrocephala koidz. J. Beijing Union Univ. (Nat. Sci.) 2009, 23, 14-18.

25. Chen, X.; Tang, Q.; Chen, Y.; Wang, W.; Li, S. Simultaneous extraction of polysaccharides from poria cocos by ultrasonic technique and its inhibitory activities against oxidative injury in rats with cervical cancer. Carbohydr. Polym. 2010, 79, 409-413. [CrossRef]

26. Zhang, C.-H.; Yu, Y.; Liang, Y.-Z.; Chen, X.-Q. Purification, partial characterization and antioxidant activity of polysaccharides from Glycyrrhiza uralensis. Int. J. Biol. Macromol. 2015, 79, 681-686. [CrossRef] [PubMed]

27. Jia, X.; Ma, L.; Li, P.; Chen, M.; He, C. Prospects of poria cocos polysaccharides: Isolation process, structural features and bioactivities. Trends Food Sci. Technol. 2016, 54, 52-62. [CrossRef]

28. Waldron, K.; Faulds, C. Cell wall polysaccharides: Composition and structure. Compr. Glycosci. 2007, 1, 181-201.

29. Maxwell, E.G.; Belshaw, N.J.; Waldron, K.W.; Morris, V.J. Pectin-An emerging new bioactive food polysaccharide. Trends Food Sci. Technol. 2012, 24, 64-73. [CrossRef]

30. Zhang, Q.; Xu, Y.; Zou, S.; Zhang, X.; Cao, K.; Fan, Q. Novel functional polysaccharides from radix polygoni multiflori water extracted residue: Preliminary characterization and immunomodulatory activity. Carbohydr. Polym. 2016, 137, 625-631. [CrossRef] [PubMed]

31. Zhang, H.; Nie, S.-P.; Yin, J.-Y.; Wang, Y.-X.; Xie, M.-Y. Structural characterization of a heterogalactan purified from fruiting bodies of ganoderma atrum. Food Hydrocoll. 2014, 36, 339-347. [CrossRef]

32. Ho, G.T.T.; Zou, Y.-F.; Aslaksen, T.H.; Wangensteen, H.; Barsett, H. Structural characterization of bioactive pectic polysaccharides from elderflowers (sambuci flos). Carbohydr. Polym. 2016, 135, 128-137. [CrossRef] [PubMed]

33. Chai, Y.; Zhao, M. Purification, characterization and anti-proliferation activities of polysaccharides extracted from Viscum coloratum (Kom.) Nakai. Carbohydr. Polym. 2016, 149, 121-130. [CrossRef] [PubMed]

34. Li, J.; Fan, L.; Ding, S. Isolation, purification and structure of a new water-soluble polysaccharide from Zizyphus jujuba cv. Jinsixiaozao. Carbohydr. Polym. 2011, 83, 477-482. [CrossRef]

35. Li, J.; Ai, L.; Yang, Q.; Liu, Y.; Shan, L. Isolation and structural characterization of a polysaccharide from fruits of Zizyphus jujuba cv. Junzao. Int. J. Biol. Macromol. 2013, 55, 83-87. [CrossRef] [PubMed]

36. Liu, W.; Liu, Y.; Zhu, R.; Yu, J.; Lu, W.; Pan, C.; Yao, W.; Gao, X. Structure characterization, chemical and enzymatic degradation, and chain conformation of an acidic polysaccharide from Lycium barbarum $\mathrm{L}$. Carbohydr. Polym. 2016, 147, 114-124. [CrossRef] [PubMed]

37. Huang, F.; Zhang, R.; Liu, Y.; Xiao, J.; Su, D.; Yi, Y.; Wang, G.; Wei, Z.; Zhang, M. Characterization and mesenteric lymph node cells-mediated immunomodulatory activity of litchi pulp polysaccharide fractions. Carbohydr. Polym. 2016, 152, 496-503. [CrossRef] [PubMed] 
38. Aw, T.Y. Molecular and cellular responses to oxidative stress and changes in oxidation-reduction imbalance in the intestine. Am. J. Clin. Nutr. 1999, 70, 557-565. [PubMed]

39. Bhattacharyya, A.; Chattopadhyay, R.; Mitra, S.; Crowe, S.E. Oxidative stress: An essential factor in the pathogenesis of gastrointestinal mucosal diseases. Physiol. Rev. 2014, 94, 329-354. [CrossRef] [PubMed]

40. DuBois, M.; Gilles, K.A.; Hamilton, J.K.; Rebers, P.T.; Smith, F. Colorimetric method for determination of sugars and related substances. Anal. Chem. 1956, 28, 350-356. [CrossRef]

41. Austarheim, I.; Christensen, B.E.; Hegna, I.K.; Petersen, B.O.; Duus, J.O.; Bye, R.; Michaelsen, T.E.; Diallo, D.; Inngjerdingen, M.; Paulsen, B.S. Chemical and biological characterization of pectin-like polysaccharides from the bark of the malian medicinal tree cola cordifolia. Carbohydr. Polym. 2012, 89, 259-268. [CrossRef] [PubMed]

42. Kim, J.B.; Carpita, N.C. Changes in esterification of the uronic acid groups of cell wall polysaccharides during elongation of maize coleoptiles. Plant Physiol. 1992, 98, 646-653. [CrossRef] [PubMed]

43. Ciucanu, I.; Kerek, F. A simple and rapid method for the permethylation of carbohydrates. Carbohydr. Res. 1984, 131, 209-217. [CrossRef]

44. Sweet, D.P.; Shapiro, R.H.; Albersheim, P. Quantitative analysis by various glc response-factor theories for partially methylated and partially ethylated alditol acetates. Carbohydr. Res. 1975, 40, 217-225. [CrossRef]

45. Zhu, Z.-Y.; Liu, R.-Q.; Si, C.-L.; Zhou, F.; Wang, Y.-X.; Ding, L.-N.; Jing, C.; Liu, A.-J.; Zhang, Y.-M. Structural analysis and anti-tumor activity comparison of polysaccharides from astragalus. Carbohydr. Polym. 2011, 85, 895-902. [CrossRef]

46. Yan, J.-K.; Li, L.; Wang, Z.-M.; Wu, J.-Y. Structural elucidation of an exopolysaccharide from mycelial fermentation of a Tolypocladium sp. fungus isolated from wild Cordyceps sinensis. Carbohydr. Polym. 2010, 79, 125-130. [CrossRef]

47. Huang, C.; Chen, M.; Pang, D.; Bi, D.; Zou, Y.; Xia, X.; Yang, W.; Luo, L.; Deng, R.; Tan, H.; et al. Developmental and activity-dependent expression of lancl1 confers antioxidant activity required for neuronal survival. Dev. Cell 2014, 30, 479-487. [CrossRef] [PubMed]

Sample Availability: Samples of the compounds SJZDP-I-I, SJZDP-I-II and SJZDP-II-I are available from the authors.

(C) 2017 by the authors. Licensee MDPI, Basel, Switzerland. This article is an open access article distributed under the terms and conditions of the Creative Commons Attribution (CC BY) license (http://creativecommons.org/licenses/by/4.0/). 